\title{
Dos derechos al revés: reflexiones sobre los derechos a la vida y a la paz en el mundo actual (a)
}

\author{
Two rights gone wrong: \\ reflections on the rights to life and \\ peace in today's world
}

Saúl Franco ${ }^{1}$

${ }^{1}$ Medico, Universidad de Antioquia, Colombia. Doctor en Salud Pública, Escuela Nacional de Salud Pública, FIOCRUZ, Brasil. Coordinador del Doctorado Interfacultades en Salud Pública, Universidad Nacional de Colombia. saulfranco@hotmail.com
RESUMEN El documento presenta una síntesis de los conceptos de vida y paz y de ambos como derechos humanos. Reconoce que en la actual situación, ambos derechos están siendo sistemática y gravemente negados al interior de muchos países y en el escenario internacional. A partir de sintetizar los aportes de diferentes disciplinas acerca de lo que es la vida, el documento se centra en el reconocimiento de la vida como el derecho esencial y como la base de todos los demás derechos.

Se presenta luego un panorama realista y muy preocupante del estado actual de ambos derechos en el mundo. Se aportan cifras y datos sobre homicidios, desplazamientos forzosos por la violencia, refugiados y secuestrados, y sobre diferentes formas de violaciones a los derechos a la vida y a la paz en algunos de los conflictos armados más agudos y representativos en la actualidad, entre ellos la invasión y consiguiente guerra en Irak, y los conflictos de Afganistán, Israel y Palestina y Sudán, con una referencia especial a la situación colombiana. El material termina señalando algunos posibles mecanismos y acciones para contribuir desde la posición de cada cual a la reducción de las violaciones a estos dos derechos humanos y a fomentar su vigencia.

PALABRAS CLAVE Derechos Humanos; Conflictos Armados; Violaciones de los Derechos Humanos; Homicidio; Violencia.

ABSTRACT This document addresses the concepts of life and peace, as well as the understanding of these two concepts as human rights. It also analyzes how both rights are being severely and systematically violated within and among countries, in the present state of world affairs. Departing from the contributions of different fields towards the concept of life, this article focuses on the recognition of life as the essential right and as the basis for all other rights.

The author then presents a realistic and worrisome view of the current state of life and peace as human rights. Statements are backed by data on homicides, forceful displacements, kidnappings and refugees in some of the most representative armed conflicts of today, including the invasion and subsequent war in Iraq and the armed conflicts of Sudan, Afghanistan, Israel-Palestine and Colombia. The article concludes with the author's view of possible mechanisms and actions whereby individuals could contribute to the promotion of life and peace, and to a reduction in the violation of these two human rights.

KEY WORDS Human Rights; Armed Conflicts; Human Rights Abuses; Homicide; Violence. 


\section{INTRODUCCIÓN}

Sé que los y las asistentes y lectores esperarían una especie de elogio apasionado de la vida y de la paz, y de ambas como derechos. Derechos, además, de primera línea, aunque no sean ambos de la llamada primera generación de derechos. Pero la realidad cotidiana, la observación cuidadosa de lo que pasa con la vida y con la paz en el mundo y en mi país, Colombia, y el estudio de parte de lo mucho que se ha escrito y se continúa escribiendo sobre estos temas, me Ilevaron a concluir que cada vez se maltrata, se desprecia y se extermina más la vida de millones y millones de seres humanos. Y que la paz es cada día más burlada y negada tanto al interior de muchos países como en el complejo y tenso escenario internacional. Es por eso que, a pesar del buen sentido y la inteligencia de los organizadores que acertadamente denominaron este debate "El Derecho a la Vida y a la Paz", me vi forzado a concluir que ambos derechos están mucho más al revés que al derecho en la sociedad contemporánea.

Ante la variedad de temas y abordajes posibles sobre las dos realidades esenciales objeto de estas anotaciones, y dado el saludable límite de tiempo asignado en un evento de esta magnitud, decidí centrarme en cuatro breves reflexiones, así:

1. La vida humana y el derecho a ella.

2. La paz: un derecho en construcción.

3. La reafirmación retórica y la negación sistemática de ambos derechos en el mundo actual.

4. Para defender la vida y construir la paz.

\section{LA VIDA HUMANA} Y EL DERECHO A ELLA

¿Qué es la vida? Como sabemos, no existe una respuesta única para esta pregunta simple. Los biólogos enfatizan la organización de la materia, en particular de los cincuenta billones de células y los treinta mil genes que conforman el cuerpo humano, y sus posibilidades de desarrollo, adaptación y reproducción.
Los fisiólogos resaltan el hecho de que los organismos vivos sean capaces de realizar funciones como moverse, comer, metabolizar y respirar. François Jacob, genetista, premio Nobel de Medicina en 1965, se arriesga a definirla como:

la fuerza oscura que confiere sus atributos a los cuerpos organizados, que mantiene las moléculas unidas, a pesar de las fuerzas exteriores que tienden a separarlas... La vida es exactamente este principio de lucha contra la destrucción (1).

Filósofos, teólogos y poetas le apuntan, en particular en el campo de la vida humana, a la creatividad, la autonomía, la capacidad de amar y la trascendencia. Pero, además, la vida se hizo también historia. Tal entrada, según Foucault, consistió en la estatalización de lo biológico, y equivale a:

la entrada de los fenómenos propios de la vida de la especie humana en el orden del saber y del poder (2).

En su sabiduría de diccionario, y tratando de conformar a todos, el de la Lengua Española la define como:

Fuerza o actividad interna sustancial, mediante la que obra el ser que la posee. Estado de actividad de los seres orgánicos (3).

En esencia, entonces: materia organizada; energía; movimiento autónomo; actividad; adaptación; lucha contra la destrucción; interrelación; en ciertas especies, inteligencia y afecto; y además, en los humanos, creatividad.

A la realización específica de esa complejidad que reconocemos como vida en cada ser humano es a lo que he venido proponiendo que Ilamemos Proceso Vital Humano (PVH). Se trata de una categoría sintética que busca además ampliar y dar sentido al mundo de la salud y la enfermedad, reafirmar el carácter dinámico e interrelacionado de nuestras existencias individuales y expresar las esenciales interacciones entre los niveles biológico, político, económico y cultural, es decir: bio-sociales (4). Es preciso reconocer que todavía es una categoría embrionaria, pero sigo pensando que está cargada de futuro. 
La aceptación, esta sí universal, de la vida como el derecho humano esencial y uno de los fundamentales, me exime de extenderme en consideraciones acerca del tipo de derecho de que se trata. Pero creo necesario hacer algunas precisiones. La primera: que el derecho a la vida no es garantía de inmortalidad. Debe serlo de que nadie tiene el derecho de arrebatarme la vida y de que la sociedad me debe garantizar todo lo necesario para sobrevivir, dignamente, como se verá a renglón seguido. $\mathrm{Y}$ así como el seguro de vida es en realidad un subsidio post-mortem, en forma casi paradójica me arriesgaré a decir que mi derecho a la vida es válido mientras esté vivo e implica que nadie tiene derecho a matarme. La segunda: que es un derecho adquirido por el simple pero maravilloso hecho de ser, de nacer $y$ ratificado por el hecho de hacer parte de colectivos que van desde la familia hasta los estados. La tercera: que el derecho a la vida no es sólo el derecho a la supervivencia. Cobija también el derecho a la dignidad, a una vida digna. Y a la convivencia con otros y con otras. Y cuarto, enfatizar lo ya enunciado: estrictamente es el único derecho esencial. Es decir: sin él ningún otro derecho es posible ni tiene sentido. Para el tema que nos ocupa: puede haber vida sin paz, pero no paz sin vida.

\section{LA PAZ: UN DERECHO EN CONSTRUCCIÓN}

Encontré un concepto subversivo y sugestivo de paz. Según el poeta de Irlanda del Norte Seamus Heaney en su discurso de aceptación del premio Nobel de literatura en 1995, para Tácito:

la paz es la desolación que queda después de las operaciones arrasadoras realizadas por un poder inmisericorde (5).

Sé que es irreverente. Pero siento que expresa un componente importante de la realidad: la paz es el saldo rojo de las guerras.

Pero, siguiendo con el pasado, encontré que, medio siglo antes de que empezara la era cristiana, Cicerón acuñó un concepto de paz que sigue siendo válido 2.057 años después. Dijo en su lengua: "Pax est tranquilla libertas" (6). En español: la paz es el goce tranquilo de la libertad. Están ahí tres de los componentes básicos de la paz que creo compartimos hasta hoy: la paz es disfrute, es decir: sensación positiva, percepción individual y colectiva de bienestar; la paz es tranquilidad, como estado sereno del ánimo personal y social; y la paz es el ejercicio de la libertad. Es, por tanto, un concepto muy afín al de salud. Podríamos decir que la paz es a la sociedad lo que la salud es al individuo. $Y$ algo esencial: la base, la materia prima de la paz es la libertad, el ejercicio y la vigencia de las libertades. Por supuesto que Cicerón no tuvo, como nosotros, la suerte de contar con los desarrollos sobre la libertad que hoy tenemos, como los formulados por Amartya Sen, para quien la libertad no es sólo el ejercicio de la autonomía sino también la obtención y el desarrollo de las capacidades humanas (7). Hoy sabemos además que para lograr el desarrollo en sociedad de las capacidades humanas se requiere un ordenamiento justo, condiciones reales de equidad y vigencia para todos de los derechos.

La paz no es entonces sólo la no-guerra, el fin de los intentos de resolver mediante las armas y la fuerza los conflictos internos y entre países. Claro está que es justamente en condiciones de guerra cuando más se sienten la ausencia y las bondades de la paz. Pero el fin de la guerra sólo es el comienzo de la paz si simultáneamente crecen la justicia, la equidad y el imperio de los derechos de todos por encima de los intereses de pocos.

Como Ustedes posiblemente sepan, en mi país vivimos hace ya más de cuatro décadas una guerra. Una guerra a veces aceptada y a veces, como hoy, negada por algunos. Pero siempre, como todas las guerras, cruel y dolorosa. En mi país en guerra, una organización Ilamada Movimiento Ciudadano por la Paz le preguntó hace diez años a muy diversas personas qué entendían por paz, textualmente: "¿Cuál es su paz?". Las respuestas fueron tan variadas que llenaron un libro de 244 páginas (8). Pues bien, por considerarlas muy pertinentes, me permito citar algunas de las respuestas dadas a esa pregunta por un escritor y ambientalista, Gustavo Wilches-Chaux: 
La paz es no tener que renunciar a los derechos del alma para poder acceder a los del cuerpo... Que nadie tenga derecho a decidir sobre la vida y la muerte de los demás. La paz es el derecho a pensar distinto, a vivir distinto, a ser distinto, a discrepar. La paz es que todos tengamos nuestro pedacito de suelo, con su correspondiente kilómetro cúbico de estrellas sobre la cabeza (8 p.12,13).

Como rigurosamente el tema en cuestión no es la paz sino el derecho a la paz, entremos en materia. Ni para los revolucionarios franceses de finales del siglo XVIII, ni para la Declaración Universal de los Derechos Humanos adoptada por la naciente Organización de las Naciones Unidas el 10 de diciembre de 1948 la paz era un derecho. Al menos no explícitamente, a pesar de haber sido promulgados en medio de una revolución y al final de una guerra, la segunda calificada de "mundial". Puede afirmarse que la formulación de la paz como derecho es una preocupación muy reciente, de finales del siglo pasado, y que éste sería uno de los derechos Ilamados "emergentes, o de tercera generación", y estaría por tanto al lado de los derechos al ambiente saludable y al desarrollo sostenible. El 12 de noviembre de 1984, la Asamblea General de las Naciones Unidas adoptó la Declaración sobre el Derecho de los Pueblos a la Paz (9). El texto, muy orientado contra la guerra y en especial contra las amenazas de guerra nuclear, dice en su parte resolutiva:

1. Proclama solemnemente que los pueblos de nuestro planeta tienen el derecho sagrado de la paz. 2. Declara solemnemente que proteger el derecho de los pueblos a la paz y fomentar su realización es una obligación fundamental de todo Estado (9).

Desafortunadamente la solemnidad de la declaración ha contrastado ya varias veces con el papel realmente cumplido por las Naciones Unidas en la salvaguarda de la paz en varias regiones ante la prepotencia de algunos Estados miembros.

Debo decir, con cierto orgullo, que mi país en guerra -y posiblemente por estar en guerra- es uno de los pocos del mundo que integró ya a su Constitución el derecho a la paz. En efecto, el artículo 22 de la nueva Constitución, convocada y aprobada en 1991 como un intento de hacer posible y fundamentar la paz, dice: "La paz es un derecho y un deber de obligatorio cumplimiento" (10). Pero tengo que decirles, con mucha vergüenza, que en los dieciséis años de vigencia de nuestra Constitución, en mi país ni el Estado ni los ciudadanos hemos podido sentir el goce tranquilo del derecho a la paz, y que la contundencia de los hechos que les daré a conocer más adelante demuestran que ni el uno ni los otros estamos cumpliendo con el deber obligatorio de la paz.

¿Qué significa en concreto el derecho a la paz? ¿Qué le agrega al concepto de paz el hecho de que sea considerada como un derecho? Como derecho individual y como derecho colectivo, la paz ha sido considerada por algunos estudiosos del tema como una especie de derecho síntesis (11) en el sentido de que la realización efectiva de muchos otros derechos -incluidos los derechos a la vida, a la libertad, a la seguridad personal, a la libre movilización- presuponen la vigencia del derecho a la paz. En otra forma: que sin paz no hay o se ponen en alto riesgo la vida, la libertad, etc. El derecho a la paz, tanto en paz como en guerra, significa el derecho a la tramitación y resolución no violenta de conflictos, a la negociación, al consenso, a la intermediación, a la reconciliación. Al mismo tiempo, el mantenimiento de condiciones de paz, y por tanto de vigencia del correspondiente derecho, presupone que los ciudadanos, en un clima de libertad y en condiciones de equidad, experimenten la realización de sus derechos a un salario justo, a una vivienda digna, a la educación y a la salud. Según el jurista antes citado, hace ya medio siglo que Hans Kelsen enseñó que "El Derecho es, por esencia, un orden para preservar la paz" (11 p.2).

\section{LA REAFIRMACIÓN RETÓRICA Y LA NEGACIÓN SISTEMÁTICA DE AMBOS DERECHOS EN EL MUNDO ACTUAL}

Posiblemente los 830.000 homicidios reportados a nivel mundial por la Organización Mundial de la Salud sólo para el año 2000 (12) constituyan una señal premonitoria y de pésimo 
pronóstico para la vigencia del derecho a la vida en el comienzo del nuevo milenio. Y como 310.000 de esos 830.000 muertos lo fueron en medio de las treinta guerras vigentes, el pronóstico no es el mejor para la vigencia del derecho a la paz. De hecho, hace pocos días, al retomar las fuerzas militares de Pakistán la Mezquita Roja de Islamabad, ocupada por militantes de un sector islámico que retuvieron varias personas, se ha producido una nueva matanza, con un saldo de muertos que oscila, según la fuente, entre 76 y 286 (13).

No son mejores las cifras en términos de desplazados internos en el mundo y de refugiados por causa de las guerras. Según el último informe de la Oficina del Alto Comisionado de las Naciones Unidas para los Refugiados (ACNR) (14):

En el año 2004 había entre 20 y 25 millones de desplazados internos. Por entonces, el número de refugiados -los huidos o expulsados de su país- había descendido desde 9,6 a 9,2 millones en 2003... Actualmente se calcula que, debido a varios conflictos, hay 1,4 millones de desplazados internos en Uganda, al menos 1,5 millones en la República Democrática del Congo y 6 millones en Sudán (14 p.153).

En nombre de la democracia, de la paz y de la lucha contra el terrorismo, se vienen iniciando, manteniendo e intensificando varias guerras internas o entre países, en la actualidad en varios continentes. Es el caso de la invasión promovida y presidida por los Estados Unidos contra Irak, un país con conflictos casi ancestrales, 23 millones de habitantes, bajas condiciones de higiene, salud y educación, un desempleo del $17 \%$ y una dictadura opresora. Pues bien, en los primeros 52 meses de esta invasión, van ya 3.600 soldados norteamericanos muertos. Y si bien la cifra de iraquíes -civiles y militares- muertos no se sabe con exactitud, se estima en más de medio millón. Tampoco son cuantificables los costos en términos de sufrimiento, humillaciones y degradaciones como las que horrorizaron al mundo desde la cárcel de Abu Ghraib, orfandad, viudez, heridas y enfermedades, pero se estima que esta acción bélica, falsamente justificada y condenada al fracaso, le está costando a los Estados Unidos 10.000 millones de dólares al mes, lo que daría hasta hoy un total de 520.000 millones de dólares.
No sólo Irak vive la pesadilla de la guerra. Ni Israel ni Palestina pueden dormir tranquilos mientras un conflicto con complejas y antiguas raíces sigue sin perspectivas de solución y agravado por el cruce de intereses geoestratégicos, entre los cuales juegan también, y en qué medida, los de los Estados Unidos. Afganistán, con guerra y miseria propias, ha visto su guerra incrementada por la cruzada antiterrorista la cual, además de miles de muertos, le ha costado el desplazamiento interno y la salida del país del $20 \%$ de su población. En algunos países africanos también se violan masivamente los derechos a la vida y a la paz. El caso de la región de Darfur, en Sudán, es escandaloso. Unos conflictos tribales por tierra, agua y comida en medio del aislamiento, la pobreza y la intolerancia, devinieron allí, y desde hace 40 años, en una guerra entre grupos armados ilegales, las fuerzas de un Estado corrupto y distante y organizaciones de tipo paramilitar. El saldo hasta hoy es trágico: más de 200.000 muertos, 230.000 refugiados en Chad, su vecino occidental, violaciones sexuales sistemáticas como arma de guerra -tal como ya habíamos visto en los Balcanes-, torturas, impunidad rampante y tres acuerdos de paz firmados desde 2003 (15), cada uno menos creíble y eficaz que el anterior.

Permítanme ahora unas breves anotaciones sobre el Conflicto Armado Interno (CAI) que padece mi país. Enraizado en una larga historia de inequidad, intolerancia e impunidad, el conflicto colombiano se ha agudizado en los últimos 40 años a raíz de la emergencia y expansión del problema del narcotráfico; a la persistencia de un Estado incapaz de enfrentar los problemas de fondo, ausente en muchas regiones del país, sumiso a los imperativos trasnacionales y con altos niveles de corrupción; y a la conformación de organizaciones armadas de tipo guerrillero -en especial las Fuerzas Armadas Revolucionarias de Colombia (FARC) y el Ejército de Liberación Nacional (ELN) - y en los últimos 25 años de organizaciones paramilitares, articuladas como Autodefensas Unidas de Colombia (AUC) (16).

La respuesta estatal ha sido ondulante entre los intentos de negociación política y los planes de resolución militar del CAI. El actual gobierno se ha empeñado tercamente en negar la 
existencia de un conflicto armado en el país, en reducir lo existente a una confrontación con núcleos terroristas, y en buscar su exterminio mediante fuertes y costosos dispositivos militares. En la actualidad puede evidenciarse una grave degradación del conflicto debido a la radicalización militarista tanto del gobierno como de las FARC, a la conversión de los medios en fines por parte de las organizaciones armadas al margen de la ley, a la infiltración del dinero, los intereses y los métodos del narcotráfico en todos los actores armados, incluyendo las fuerzas armadas estatales, a las violaciones sistemáticas de los Derechos Humanos, del Derecho Internacional Humanitario -incluidos crímenes de lesa humanidad- y de la Misión Médica por parte de todos los actores armados (17). La situación se ha complicado aun más con el denominado "escándalo de la parapolítica", consistente en el progresivo reconocimiento de fuertes y antiguos vínculos entre numerosos dirigentes políticos y las organizaciones, actividades y crímenes de los paramilitares. En la actualidad 24 parlamentarios, incluidos un primo del actual presidente de la República y varios de sus más cercanos amigos y compañeros de actividad política, están siendo investigados por las autoridades judiciales por dichos vínculos.

En su Informe sobre Colombia, correspondiente al año 2006 (18), el Alto Comisionado de las Naciones Unidas para los Derechos Humanos afirmó:

Pudo observarse la existencia de un patrón de ejecuciones extrajudiciales y de desapariciones forzadas, asociadas a violaciones vinculadas a la administración de justicia y a la impunidad. También se registraron detenciones arbitrarias, torturas y tratos crueles, inhumanos o degradantes y atentados contra la libertad de expresión (18 p. 2).

Entre 1975 y 2004 se registraron un total de 554.008 homicidios en el país, lo que da un promedio de un homicidio cada media hora durante 30 años (19). Con varios agravantes. El primero: que la mayor parte de las víctimas pertenecen a la población joven, especialmente hombres. El segundo: que algunas de esas muertes se produjeron en condiciones de total indefensión, como los casos de las masacres -asesinatos colectivos- y los asesinatos de personal secuestrado, como ocurrió recientemente con la muerte en cautiverio y en condiciones aún desconocidas de once diputados de la Asamblea Regional del Departamento del Valle del Cauca, secuestrados por las FARC. A propósito: no tengo ninguna duda ni de la plena responsabilidad de las FARC, ni de la corresponsabilidad del actual gobierno en este bárbaro y doloroso acontecimiento, tal como valerosamente lo han manifestado algunos parientes de las víctimas y diferentes sectores sociales. Y el tercero: que esa cifra no incluye a miles de personas asesinadas por las organizaciones armadas y enterradas sin identificación en fosas comunes. Al respecto, el Informe de Amnistía Internacional ya citado dice:

Se hallaron más de 80 fosas comunes que contenían los restos de unas 200 personas asesinadas por grupos paramilitares en el curso del conflicto. La Unidad Nacional de Justicia y Paz afirmó que seguían sin localizarse los restos de unas 3.000 víctimas de desaparición forzada, aunque se creía que esa cifra era muy inferior a la verdadera (17 p.133).

Dos datos finales. Uno sobre el desplazamiento forzado por el conflicto armado colombiano y otro sobre el grave problema del secuestro en el país. De conformidad con la información suministrada por ACNUR, Colombia es, después de Sudán, el país con el mayor número de desplazados en el mundo: dos millones registrados por la entidad a finales de 2004 (14 p.211). Es preciso señalar que el desplazamiento forzoso conlleva una violación general de los más elementales derechos humanos y genera graves consecuencias psicológicas, afectivas, económicas, demográficas y sociales. Por su parte, en los últimos diez años, 1996-2005, se han registrado en el país un total de 23.319 secuestros, lo que da un promedio anual durante la década de 2.331 secuestros, es decir: 6,4 secuestros por día, teniendo claro que los secuestros realmente ocurridos son muchos más que los registrados. 


\section{PARA DEFENDER LA VIDA Y CONSTRUIR LA PAZ}

Sería ingenuo o presuntuoso en exceso pretender terminar estas reflexiones presentando fórmulas universales para problemas de inmensa complejidad particular, o propuestas voluntaristas y utópicas para tratar de fomentar la defensa de la vida y la construcción de la paz en el mundo de hoy. Sé que la vida y la paz se juegan tanto en las grandes ligas de los macropoderes mundiales y nacionales como en la cotidianidad de cada uno de nosotros. Me limitaré a constatar algunos hechos positivos del lado de la vida y de la paz y a esbozar algunas tareas realistas.

El primero: a pesar del panorama de guerras y muerte anteriormente presentado, hay muchas evidencias de lo que podríamos Ilamar el triunfo de la vida sobre la muerte y de las luchas en curso para defender la paz y la vida en dignidad para muchos seres humanos. El hecho elemental de que cada año sea mayor el saldo de nuevos seres humanos que el de muertos es un primer indicador. Nos estamos aproximando a los 7.000 millones de humanos habitantes de este planeta. Pero no es sólo una cuestión de número de nuevas vidas humanas. Es que, aun en las más difíciles condiciones, encontramos cada día casos emblemáticos de personas, organizaciones y hasta Estados que dedican sus mejores esfuerzos a tratar de hacer más digna y amable la vida en el mundo para todos sus habitantes, incluidos los humanos. No abundaré en ejemplos por motivos de espacio y justicia. Pero sé que cada uno y cada una ha tenido más de una oportunidad de conocer y hasta participar en esfuerzos y experiencias que nos reconcilian con la vida y nos dan fuerzas para seguir adelante.

Igual acontece con los esfuerzos por la paz y su vigencia como derecho. En las dos últimas décadas, y aun en medio de conflictos agudísimos que parecían insolubles y de guerras feroces, se han logrado acuerdos de paz que han germinado y aliviado la vida de muchas personas y de algunos países. Tales son los casos, por ejemplo, de Guatemala y El Salvador en Centroamérica y de Irlanda del Norte. Por su parte Sudáfrica, cumplió ya 13 años de haber superado la fase más aguda de su conflicto racial y ha avanzado de manera significativa en el camino de la libertad y la paz.

El arzobispo sudafricano Desmond Tutu ha expresado repetidamente que "la paz es posible" (20). El enunciado quiere ser positivo y estimulante, pero no deja de tener un cierto sabor de resignación y hasta de desesperanza que podría expresarse así: ¿de qué sirve que la paz sea posible si no es real y efectiva? Habría que empezar desde más atrás para poder salir adelante. Me atrevo a afirmar: hay que hacer posible la paz. Es decir: tanto en condiciones de paz como de guerra hay que trabajar, día a día y desde cualquier lugar social o geográfico, para construir las precondiciones de la paz (justicia, equidad, respeto, tolerancia de lo tolerable, negociación) y, en casos de conflictos armados, para contribuir a quitarle piso y a derrotar los militarismos y las guerras de exterminio y abrir camino a procesos de negociación y acuerdos políticos.

Como estoy empezando a caer en lo que no quería caer, termino aquí diciendo que, entre otros, veo muy posible dar algunos pasos positivos en el sentido de enderezar lo que está al revés. El primero: mantener siempre viva la capacidad de sorpresa y de reacción frente a cualquier injusticia y a cualquier imperialismo, no importa su color o su apariencia. El segundo: reafirmar que nuestro compromiso y nuestra militancia esencial es con la vida y es por la vida digna y amable para todos. Y el tercero: detectar y valorar los hechos positivos -grandes o pequeños- que cada día vemos del lado de la vida y de la paz, recuperarlos, apoyarlos, divulgarlos y multiplicarlos. Puede ser poco. Pero es algo posible y es en la dirección correcta. 


\section{NOTAS FINALES}

a. Ponencia presentada en el XIV Congreso de la Asociación Internacional de Políticas de Salud, X Congreso de la Asociación Latinoamericana de Medicina Social, y IV Conferencia de Ciencias Sociales y Humanas en Salud. Salvador de Bahía, Brasil, 17 de julio de 2007.

\section{REFERENCIAS BIBLIOGRÁFICAS}

1. Jacob F. A Lógica da Vida: uma historia da hereditariedade. Río de Janeiro: Graal; 1983. p. 97.

2. Garcés M. Life as a political concept. A reading of Michel Foucault and Gilles Deleuze. Athenea Digital. 2005;(7):87-104.

3. Real Academia de la Lengua. Diccionario de la Lengua Española. 22a ed. Madrid: Espasa Calpe; 2001. Tomo II p. 2297.

4. Franco S. Proceso Vital Humano y Proceso Salud-Enfermedad: una nueva perspectiva. En: Ética, Universidad y Salud. Bogotá: Universidad Nacional de Colombia, Ministerio de Salud; 1993.

5. Heaney S. En honor de la poesía. En: Discursos Premios Nobel. Bogotá: Común Presencia Editores; 2003. Tomo II p. 89.

6. Blánquez FA. Diccionario Latino-Español. Barcelona: Editorial Ramón Sopena; 1954. p. 822.

7. Sen A. La Salud en el Desarrollo. Bulletin of the World Health Organization. 1999;77(8):619-623.

8. Unicef, Oficina de Área para Colombia y Venezuela. Mandato Ciudadano por la Paz. Eclipse de la guerra. Santa Fe de Bogotá: Editora Guadalupe; 1998.
9. Alto Comisionado de las Naciones Unidas para los Derechos Humanos. Declaración sobre el Derecho de los Pueblos a la Paz [en línea] Adoptada por la Asamblea General, resolución 39/11, 12 de noviembre de 1984 [fecha de acceso 12 de julio de 2007] URL disponible en: http://www.uasb.edu.ec/padh/revista17/documentos/declaracionpaz.htm

10. República de Colombia. Constitución Política, 1991. Santa Fe de Bogotá: Ecoe Ediciones; 1995. p. 5.

11. Gros Espiell H. El Derecho a la Paz y al Desarrollo [conferencia en línea] Organismo para la Proscripción de las Armas Nucleares en América Latina y el Caribe. 1995 [fecha de acceso 10 de julio de 2007] URL disponible en: http://www.opanal.org/Articles/cancun/canGros.htm

12. World Health Organization. World Report on violence and healt. Ginebra: WHO; 2002. p. 10.

13. Periódico El Tiempo. Jueves 12 de julio de 2007. Bogotá. p. 1-8.

14. Alto Comisionado de las Naciones Unidas para los Refugiados. La situación de los refugiados en el mundo. Desplazamientos humanos en el nuevo milenio. Barcelona: ACNUR; 2006.

15. Naciones Unidas, Consejo de Derechos Humanos. Asamblea general. Cuarto período de 
seciones [documento en línea] A/HRC/4/80, 9 de marzo de 2007 [fecha de acceso 10 de junio de 2007]. URL disponible en: http://daccess-ods. un.org/TMP/3710462.html

16. Franco S. El Quinto: No Matar. Contextos explicativos de la violencia en Colombia. Bogotá: IEPRI, Tercer Mundo Editores; 1999.

17. Amnistía Internacional. Informe 2007. El estado de los derechos humanos en el mundo. Madrid: Editorial Ammistía Internacional; 2007. p. 131-136.

18. Naciones Unidas. Comisión de Derechos Humanos. $62^{\circ}$ período de sesiones [documento en línea] E/CN.4/2006/9. 20 de enero de 2006.
[Fecha de acceso 12 de junio de 2007]. URL disponible en: http://www.hchr.org.co/documentoseinformes/informes/altocomisionado/Informe20 05_esp.doc

19. Franco S, Suárez C, Naranjo C, Báez C, Rozo $P$. The effects of the armed conflict on the life and health in Colombia. Ciencia e Saúde Coletiva. 2006;11(2):349-361.

20. Tutu D. La paz es posible. [Conferencia magistral en línea] Proveniente del Simposio Internacional sobre justicia restaurativa y paz en Colombia; 9 al 12 de febrero de 2005; Cali, Colombia. [fecha de acceso 12 de junio de 2007] URL disponible en: http://www.justicia-restaurativa-colombia.org/pages/article.php? = es\&id $=10$

\section{FORMA DE CITAR}

Franco S. Dos derechos al revés: reflexiones sobre los derechos a la vida y a la paz en el mundo actual. Salud Colectiva. 2007;3(3):315-323.

Recibido el 23 de julio de 2007

Versión final presentada el 12 de septiembre de 2007

Aprobado el 20 de octubre de 2007 